\title{
Effect of Propranolol on Hyphae Formation Signal in Candida albicans
}

\author{
Yukihiro Ueno, Naoko Maruyama, Mika Kanno, Toshihiko Watanabe, Ayako Ogasawara, \\ Takeshi Miкami, and Tatsuji Matsumoto*
}

Department of Microbiology, Tohoku Pharmceutical University; Sendai 981-8558, Japan.

Received May 15, 2008; accepted October 11, 2008; published online October 23, 2008

\begin{abstract}
Candida albicans ( $C$. albicans) is known as an opportunistic pathogen that changes from a yeast form to a hyphae form in response to various outside environmental signals. The addition of propranolol inhibited hyphae formation of $C$. albicans. Propranolol inhibited the expression of agglutinin like sequence 3 (ALS3) and ALS8mRNA, which are regulated by the cAMP-EFG1 pathway in $C$. albicans. Propranolol did not affect the expression of CST20, HST7 or CPH1mRNA, which are components of the mitogen-activated protein (MAP) kinase cascade in $C$. albicans. The expression of CYR1mRNA, which encodes adenylate cyclase of $C$. albicans, was not affected by propranolol. These findings indicated that the interruption of hyphae formation by propranolol is caused by inhibition of the cAMP-EFG1 pathway, but not effects on the MAP kinase cascade.
\end{abstract}

Key words Candida albicans; propranolol; EFG1; agglutinin like sequence 3; agglutinin like sequence 8

Candida albicans is a dimorphic fungus demonstrating two forms, a hyphae form and a yeast form, according to the growth conditions. ${ }^{1-3)}$ Usually, $C$. albicans exists in the human oral cavity, intestine, vagina and skin in a yeast form. When a host lapses into an immune-deficient state due to AIDS, malignant tumor, organ transplantation or diabetes, the hyphae form of $C$. albicans grows with increased pathogenicity in the host. ${ }^{4-7)}$

Serum is known to be an external factor affecting hyphae formation of $C$. albicans. ${ }^{8,9)}$ As shown in Fig. 1, hyphae transformation is induced by activation of the mitogen-activated protein (MAP) kinase cascade and the cAMP pathway, which are controlled by RAS protein. ${ }^{10-12)}$ Previous reports demonstrated that EFG1 is present downstream at the RAS1cAMP pathway. ${ }^{13-15)}$ EFG1 is a transcription factor and EFG1-deficient mutants are unable to form hyphae despite the presence of serum. ${ }^{16,17)}$ Hyphae-specific proteins such as agglutinin like sequence 3 (ALS3) and ALS8 are cell wall proteins in $C$. albicans, and the expressions are regulated by EFG1. ${ }^{18,19)}$

Propranolol is a human $\beta$ adrenergic receptor blocking agent. $^{20)}$ Propranolol inhibits hyphae formation of $C$. albicans, ${ }^{21)}$ however, the effects on hyphae formation signals are unknown.

In this report, we analyzed the effects of propranolol on the MAP kinase cascade and the cAMP-EFG1 pathway by measuring changes in the hyphae formation signals.

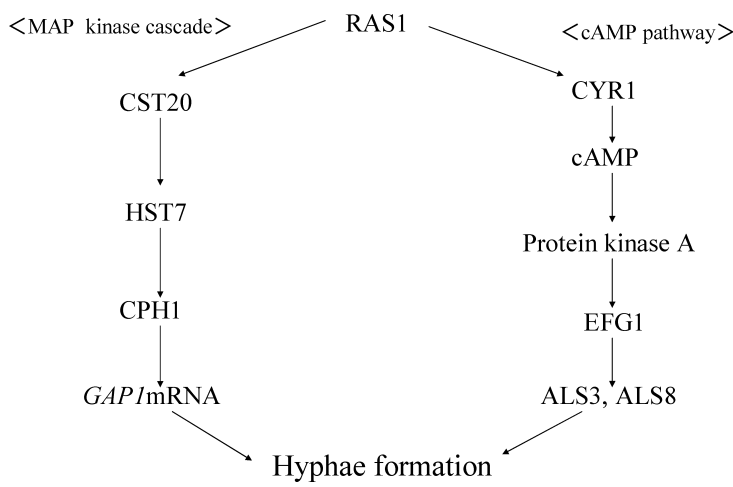

Fig. 1. RAS1-cAMP-EFG1 Pathway and MAP Kinase Cascade

\section{MATERIALS AND METHODS}

Reagents Propranolol was purchased from Sigma Chemical (St. Louis, MO, U.S.A.).

Organism and Growth Conditions C. albicans NIH A207 strain was routinely grown at $30^{\circ} \mathrm{C}$ in Sabouraud's medium ( $10 \mathrm{~g}$ peptone, $20 \mathrm{~g}$ glucose and $5 \mathrm{~g}$ yeast extract per liter). To induce hyphae formation, the cells were grown in Sabouraud's medium with $10 \%$ fetal bovine serum (FBS) at $37^{\circ} \mathrm{C}$.

Growth form of $\boldsymbol{C}$. albicans Treated with Propranolol C. albicans cells were grown to the stationary phase for $24 \mathrm{~h}$, then the cell density was adjusted to $1 \times 10^{5}$ cells $/ \mathrm{ml}$ with Sabouraud's medium containing 10\% FBS. Propranolol (final concentration, $1.0 \mathrm{~mm}$ ) was added to the cell suspension and the cells were incubated for 1,3 and $5 \mathrm{~h}$ at $37^{\circ} \mathrm{C}$. After the incubation, the ratio of hyphae cells was counted microscopically.

Reverse Transcription-Polymerase Chain Reaction (RT-PCR) Analysis C. albicans cells $\left(1 \times 10^{5}\right.$ cells $/ \mathrm{ml}$ in Sabouraud's medium containing 10\% FBS) were incubated with propranolol for $5 \mathrm{~h}$ at $37^{\circ} \mathrm{C}$. Total RNA of the cells was synthesized with a Mag Extractor-RNA- (Toyobo Co., Ltd., Japan). A cDNA library of the cells was synthesized with a Cell-to-cDNA kit (Ambion Inc., U.S.A.). PCR reaction $\left(94{ }^{\circ} \mathrm{C}\right.$ 2-min denaturation, $94{ }^{\circ} \mathrm{C} 15$-s denaturation $-64{ }^{\circ} \mathrm{C}$ 30 -s annealing $-68^{\circ} \mathrm{C} 1$-min elongation for 30 cycles $-68^{\circ} \mathrm{C} 7$-min elongation) was conducted with a KOD-plus kit (Toyobo Co., Ltd.). Primers used in this assay are shown in Table 1. PCR products were analyzed using an Agilent 2100 Bioanalyzer (Agilent Technologies, U.S.A.). The result was shown as the mRNA expression relative to that of total RNA.

Statistical Analysis Values are shown as means \pm S.E., and statistical analysis of these data was performed using Students $t$-test. $p<0.05$ was considered significant.

\section{RESULTS AND DISCUSSION}

C. albicans cultured in Sabouraud's medium containing $10 \%$ FBS generally grows in hyphae form. When propranolol was added to the cell suspension, the inhibition of germ 
Table 1. DNA Primer Sequence of C. albicans

\begin{tabular}{ll}
\hline \hline \multicolumn{1}{c}{ Primer } & \multicolumn{1}{c}{ Sequence $\left(5^{\prime} \rightarrow 3^{\prime}\right)$} \\
\hline CYR1 (sense) & GAAAAACATGATCCAACCAATCGT \\
CYR1 (antisense) & GACAATGACGCAAATTTATCGGT \\
EFG1 (sense) & ATAGTAATATCCCGTATCCGTTTCGG \\
EFG1 (antisense) & CAATTCTAACACAATAGCTCGTCTCGT \\
ALS3 (sense) & GATTGAATGATTGGAATTATCCGGT \\
ALS3 (antisense) & TTTCAATTGTCTTAGTTTTGTCGCG \\
ALS8 (sense) & GATTGAATGATTGGAATTATCCGGT \\
ALS8 (antisense) & TTTCAATTGTCTTAGTTTTTCGCG \\
CST20 (sense) & CTTCAATTCCTAAATCAAAGTCGCATT \\
CST20 (antisense) & TGCTTGCAGAGGAGCAGTACG \\
HST7 (sense) & GGAGGATGATAACAATAATGACGACG \\
HST7 (antisense) & TTTGCATTTTCTGATCTTTTCGC \\
CPH1 (sense) & TTTTTTGTTCCCGTTAACCG \\
CPH1 (antisense) & AGTAAAATTGCTTGGCAATATAGGACG \\
\hline
\end{tabular}

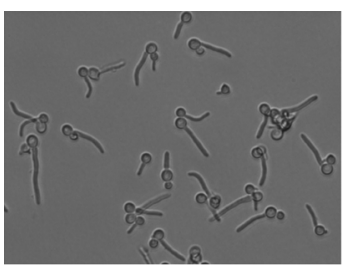

Propranolol (-)

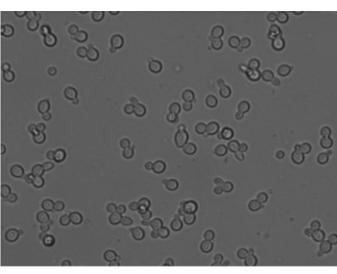

Propranolol (+)
Fig. 2. Growth form of C. albicans Cultured with Propranolol

C. albicans was cultured with/without $1.0 \mathrm{~mm}$ propranolol in Sabouraud's medium containing $10 \% \mathrm{FBS}$ at $37^{\circ} \mathrm{C}$ for $5 \mathrm{~h}$. After incubation, the growth forms of C. albicans were observed microscopically $(\times 600)$.

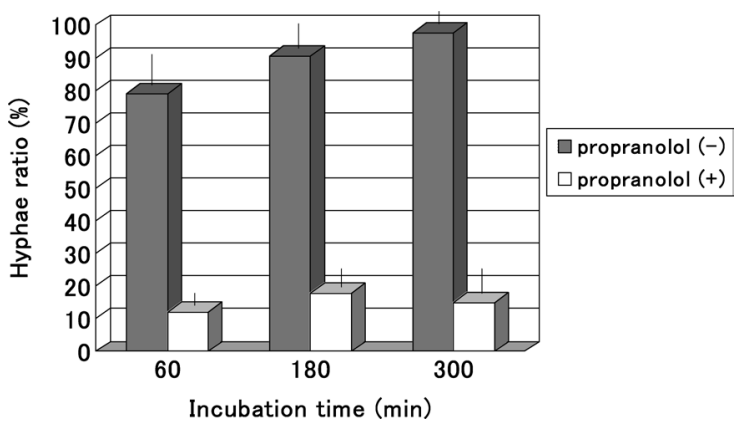

Fig. 3. Hyphae Ratio of C. albicans Treated with Propranolol

C. albicans $\left(1 \times 10^{5}\right.$ cells $/ \mathrm{ml}$ in Sabouraud's medium containing $\left.10 \% \mathrm{FBS}\right)$ was incubated with/without $1.0 \mathrm{~mm}$ propranolol at $37^{\circ} \mathrm{C}$ for 1,3 and $5 \mathrm{~h}$. After incubation, the ratio of hyphae cells was measured.

tube elongation of $C$. albicans was observed microscopically (Fig. 2). As shown in Fig. 3, the ratio of hyphae formation was significantly inhibited by propranolol. These findings suggested that propranolol regulated the hyphae transformation of C. albicans cells.

To clarify the effect of propranolol on hyphae-formation signals in C. albicans, the expressions of EFG1, ALS3 and ALS8mRNAs in the cAMP-EFG1 pathway were measured. The ALS family gene is related to the growth and morphological change of C. albicans. Especially, ALS3 and ALS8 are important in the yeast-to-hyphae transformation of $C$. albicans. ${ }^{22)}$ Thus, we measured the expression of these mRNAs to estimate the effect of propranolol on hyphae transformation signals.

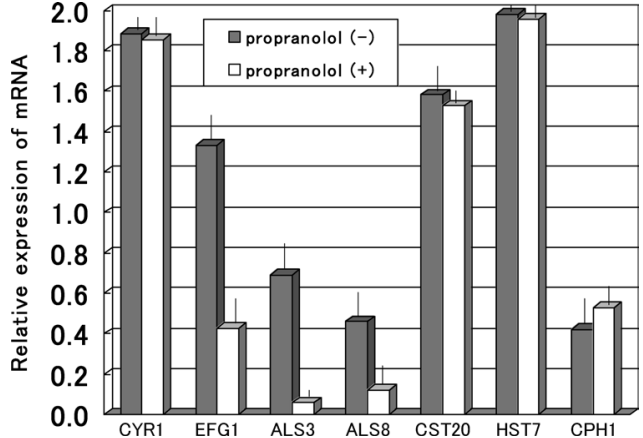

Fig. 4. Relative Expressions of mRNAs in C. albicans Treated with Propranolol

C. albicans $\left(1 \times 10^{5}\right.$ cells $/ \mathrm{ml}$ in Sabouraud's medium containing $10 \%$ FBS $)$ was incubated with/without $1.0 \mathrm{~mm}$ propranolol at $37^{\circ} \mathrm{C}$ for $5 \mathrm{~h}$. After incubation, the relative expressions of mRNAs were measured as described in Materials and Methods.

The relative mRNA expressions of EFG1, ALS3 and ALS8 were inhibited by $1.0 \mathrm{~mm}$ of propranolol (Fig. 4). As less than $1.0 \mathrm{~mm}$ of propranolol did not inhibit the hyphae formation and the expression EFG1mRNAs (data not shown), we estimated that more than $1 \mathrm{~mm}$ of propranolol was required for inhibition. CST20, HST7 and CPH1 are components of the MAP kinase cascade and the relative expressions of these mRNAs were not affected by $1.0 \mathrm{~mm}$ of propranolol, indicating that propranolol inhibited hyphae formation of C. albicans by interrupting the cAMP-EFG1 pathway, but did not affect the MAP kinase cascade.

Adenylate cyclase is a component of the cAMP-EFG1 pathway, and CYRI encodes adenylate cyclase of $C$. albicans. ${ }^{23)}$ The expression of CYR1mRNA was not affected by propranolol (Fig. 4). The levels of cAMP of C. albicans treated with/without propranolol did not differ (data not shown). These findings indicated that propranolol inhibited the region downstream to cAMP in the cAMP-EFG1 pathway, but did not inhibit the function of CYR1.

As the addition of propranolol inhibited the cAMP-EFG1 pathway of $C$. albicans, it was shown that EFG1 expression could be controlled by extra-cellular stimulation medicine. Although propranolol is used as $\beta$ receptor blocker in clinical medicine, the recommended blood level $(50-100 \mathrm{ng} / \mathrm{ml})^{24)}$ for treatment greatly differ from the concentration for inhibition of the hyphae formation. Thus, propranolol might not be useful as a treatment for C. albicans infection. However, it is expected that some propranolol derivatives would effectively control the expression of EFG1 and hyphae transformation of C. albicans. We expect that our experiment will pioneer the development of new antifungal treatments.

\section{REFERENCES}

1) Noverr M. C., Huffnagle G. B., Infect. Immun., 72, 6206-6210 (2004).

2) Bailey D. A., Feldmann P. J., Bovey M., Gow N. A., Brown A. J., J. Bacteriol., 178, 5353-5360 (1996).

3) de Groot P. W., de Boer A. D., Cunningham J., Dekker H. L., de Jong L., Hellingwerf K. J., de Koster C., Klis F. M., Eukaryot. Cell, 3, 955-965 (2004).

4) Gilfillan G. D., Sullivan D. J., Haynes K., Parkinson T., Coleman D. C., Gow N. A., Microbiology, 144, 829-838 (1998).

5) Haneke E., Semin. Dermatol., 10, 41-53 (1991).

6) Pongsiriwet S., Iamaroon A., Sriburee P., J. Oral Sci., 46, 101-105 (2004). 
7) Clemons K. V., Stevens D. A., Antimicrob. Agents Chemother, 45, 3433 -3436 (2001).

8) Enloe B., Diamond A., Mitchell A. P., J. Bacteriol., 182, 5730-5736 (2000).

9) Chiew Y. Y., Shepherd M. G., Sullivan P. A., Arch. Microbiol., 125, 97-104 (1980).

10) Chen J., Zhou S., Wang Q., Chen X., Pan T., Liu H., Mol. Cell. Biol., 20, 8696-8708 (2000).

11) Cloutier M., Castilla R., Bolduc N., Zelada A., Martineau P., Bouillon M., Magee B. B., Passeron S., Giasson L., Cantore M. L., Fungal Genet. Biol., 38, 133-141 (2003).

12) Schroppel K., Sprosser K., Whiteway M., Thomas D. Y., Rollinghoff M., Csank C., Infect. Immun., 68, 7159-7161 (2000).

13) Felk A., Kretschmar M., Albrecht A., Schaller M., Beinhauer S., Nichterlein T., Sanglard D., Korting H. C., Schafer W., Hube B., Infect. Immun., 70, 3689-3700 (2002).

14) Jung W. H., Stateva L. I., Microbiology, 149, 2961-2976 (2003).

15) Phan Q. T., Belanger P. H., Filler S. G., Infect. Immun., 68, 34853490 (2000).
16) Bachewich C., Thomas D. Y., Whiteway M., Mol. Biol. Cell, 14, 2163-2180 (2003).

17) Rademacher F., Kehren V., Stoldt V. R., Ernst J. F., Microbiology, 144, 2951-2960 (1998).

18) Zhao X., Oh S. H., Cheng G., Green C. B., Nuessen J. A., Yeater K., Leng R. P., Brown A. J., Hoyer L. L., Microbiology, 150, 2415-2428 (2004).

19) Stoldt V. R., Sonneborn A., Leuker C. E., Ernst J. F., EMBO J., 16, 1982-1991 (1997).

20) Safar M. E., Laurent S. A., London G. M., J. Cardiovasc. Pharmacol., 16, 33-35 (1990).

21) Baker C. A., Desrosiers K., Dolan J. W., Antimicrob. Agents Chemother, 46, 3617-3620 (2002).

22) Lois L. Hoyer, Trends Microbiol., 9, 176-180 (2001).

23) Jain P., Akula I., Edlind T., Antimicrob. Agents Chemother, 47, 31953201 (2003).

24) Ahnoff M., Ervik M., Lagerström P. O., Persson B. A., Vessman J., J. Chromatogr., 340, 73-138 (1985). 